Jurnal

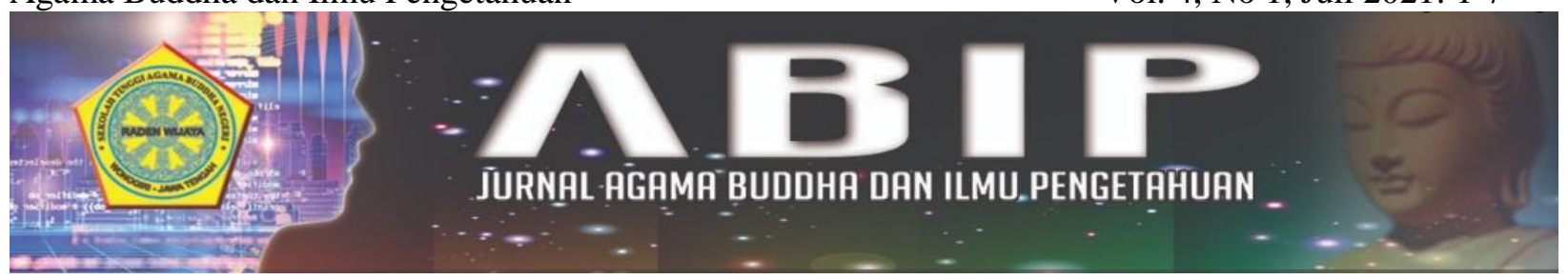

\title{
SIGNIFIKANSI GURU AGAMA BUDDHA VIHARA BUDDHA MANGGALA DALAM MEMPERKOKOH KEYAKINAN UMAT BUDDHA TERHADAP BUDDHADHAMMA
}

\author{
Rangga \\ Sekolah Tinggi Agama Buddha (STAB) Kertarajasa. \\ ranggadayak98@gmail.com
}

\begin{abstract}
Abstrak
Pentingnya seorang guru Agama secara umum adalah sebagai tugas pendidikan meliputi mendidik, mengajar, dan melatih. Seorang guru juga sangat penting untuk membantu siswa dalam mengembangkan keterampilan serta pengetahuan siswa. Oleh karena itu, guru harus bisa membuat siswanya tertarik untuk mengikuti pelajaran. Maka dari itu pentingnya seorang guru Agama Buddha dalam membimbing umat Buddha agar semangat dalam mengikuti kegiatan yang ada di Vihara Buddha Manggala, sehingga dapat memperkokoh keyakinan umat Buddha terhadap Buddhadhamma. Dengan bertambahnya keyakinanan terhadap Buddhadhamma membuat umat yang ada di Desa tidak akan berpindah keyakinan. Penelitian ini bertujuan untuk mengetahui pengaruhnya seorang guru Agama Buddha dalam memperkokoh keyakinan umat yang ada di Vihara Buddha Manggala Desa Buluh Kuning. Metode yang digunakan adalah metode penelitian lapangan kategori deskriptif kualitatif, dan menetapkan fokus penelitian yaitu: Signifikansi Guru Agama Buddha Vihara Buddha Manggala Dalam Memperkokoh Keyakinan Umat Buddha Terhadap Buddhadhamma.
\end{abstract}

Kata Kunci: Signifikansi guru, Keyakinan, Buddhadhamma;

\section{Abstract}

The importance of a religion teacher in general is an educational task which includes educating, teaching, and training. A teacher is very important to assist students in developing students' skills and knowledge. Therefore, the teacher must be able to make students interested in following the lesson. The importance of a Buddhist teacher in guiding Buddhists to be enthusiastic in participating in the activities at Manggala Buddhist Temple, so for strengthen Buddhist belief in the Buddhadhamma. With increasing belief in Buddhadhamma, people in the village will not change their beliefs. This study aims to determine the influence of a Buddhist teacher in strengthening the beliefs of the people in Manggala Buddhist Temple, Buluh Kuning Village. The method used is a qualitative descriptive, and sets the focus of the research, namely: The Significance of Buddhist Teachers at the Manggala Buddhist Temple in Strengthening Buddhist Beliefs in Buddhadhamma.

Keywords: Significance of teachers, Strengthening, Buddhadhamma 
Jurnal

Agama Buddha dan Ilmu Pengetahuan

Vol. 4, No 1, Juli 2021: 1-7

\section{PENDAHULUAN}

Salah satu masalah pokok pendidikan yang dihadapi oleh bangsa Indonesia adalah upaya peningkatan mutu pendidikan, baik mutu pendidikan dari jenjang sekolah dasar sampai pada jenjang perguruan tinggi. Pemerintah Indonesia telah melakukan berbagai usaha untuk mewujudkan hal tersebut. Misalnya dengan pengembangan pembeharuan sistem instuksional, penggantian dan penyusunan kurikulum baru yang disesuaikan dengan perkembangan zaman, pengadaan sarana dan prasarana serta pelatihan-pelatihan untuk meningkatkan mutu para guru.

Keberadaan Pendidikan Agama Buddha (PAB) dalam struktur program pengajaran di sekolah sangat penting karena PAB merupakan pengajaran tentang keluhuran budi pekerti, nilai-nilai kehidupan yang memberikan pengetahuan dan membentuk sikap, kepribadian, dan keterampilan siswa dalam mengamalkan ajaran agamanya yang dilaksanakan sekurang-kurangnya melalui mata pelajaran atau kuliah pada semua jalur, jenjang, dan jenis pendidikan.

Dalam masyarakat Buddhis karena kurangnya mendapatkan guru Agama Buddha, terutama yang berada di desa yang terpencil, mengakibatkan banyak anak sekolah yang harus pindah agama. Karena mereka membutuhkan nilai dari guru agama mereka masing-masing. Bahkan tidak hanya anak-anak yang berpindah keyakinan dari Buddhadhamma akan tetapi umat yang ada di Vihara Buddha Manggala Desa Buluh kuning, Kecamatan Sungai durian, Kabupaten Kotabaru Kalimantan selatan. Hal ini sangat penting, untuk mendapatan guru Agama yang ada di desa tersebut, sehingga apabila ada guru agama Buddha yang ada di desa dapat membimbing anak-anak ataupun masyarakat untuk tetap memiliki keyakinan terhadap Buddhadhamma.

Berdasarkan hal tersebut di atas, keberadaan guru agama Buddha menjadi penting dalam membimbing anak-anak serta masyarakat yang ada di desa Buluh kuning Vihara Buddha Manggala agar tidak berpindah keyakianan. Hal ini bisa dilakukan guru dengan cara memberikan motivasi Dhamma kepada umat-umat yang ada di Vihara Buddha Manggala, bisa juga dengan mengajak umat -umat untuk aktif datang ke Vihara guna untuk menumbuhkan keyakinan terhadap Buddhadhamma

\section{METODE}

Dalam menentukan lokasi atau tempat penelitian sangat penting, hal ini berkaitan dengan objek yang sarana dimana data yang dicari dapat diperoleh. Berdasalkan hal tersebut, maka penelitian ini dilaksanakan di Desa Buluh Kuning Kecamatan Sungai Duria Kabupaten Kotabaru Kalimantan Selatan. Desa Buluh Kuning ini dipilih sebagai tempat penelitian, karena di Desa Buluh Kuning ada Vihara atau temapat ibadah Agama Buddha. Adapun waktu yang digunakan untuk melakukan pencarian data dalam penelitian.

Desain penelitian adalah keseluruhan proses yang diperlukan dalam perancangan dan pelaksanaan penelitian, sehingga pertanyaan-pertanyaan yang ada dapat dijawab. Pengertian desain penelitian merupakan yang menentukan pelaksanaan selanjutnya, penyusunan desain ini dilakukan setelah menetapkan topik atau judul penelitian yakni penelitian yang akan dilaksanakan. Penelitian ini dikategorikan penelitian lapangans yakni penelitian yang langsung dilaksanakan di lapangan dalam pencarian data primer untuk mendapatkan data yang akurat dan kemudian didukung oleh data-data sekunder. Penelitian ini menggunakan penelitian lapangan (Field research) kategori deskriptif kualitatif, yaitu suatu prosedur yang menghasilkan data deskriptif berupa kata-kata tertulis atau lisan dari orang-orang atau yang telat diamati. Selebihnya adalah data tambahan seperti 
Jurnal

dokumen dan lain-lain (Moleong, 2017). Maksudnya adalah menguraikan permasalahan tertuju pada uraian yang lebih khusus kemudian diambil pemecahan masalah. Selain itu, bertujuan mengumpulkan fakta dan menguraikan secara menyeluruh, selanjutnya diteliti sesuai dengan persoalan yang akan dipecahkan.

Data merupakan bahan penting yang digunakan oleh peneliti untuk menjawab pertanyaan atau menguji hipotesisi dan mencapai tujuan penelitian. Oleh karena itu, kualitas data lebih penting dalam penelitian untuk menentukan hasil penelitian. Dalam penelitian ini, data diperoleh dari tinjauan langsung di lapangan. Alat yang digunakan dalam pengumpulan data dilakukan dengan: Metode Wawancara, Metode Observasi, dan Metode Dokumentasi

\section{HASIL}

Hasil penelitian membahas mengenai data yang diperoleh dilapangan atau lokasi yang digunakan. Penelitian yang dilakukan dari akhir April 2021 sampai Juli 2021 ada beberapa hal yang diperoleh dari hasil pengamatan itu. Gambaran umum wilayah Kabupaten Kotabaru dapat dilihat dari kondisi geografis, kondisi demografi dan kondisi sosial ekonomi.

Secara geografis kabupaten Kotabaru terletak antara 2o20'-4o21' Lintang Selatan dan 115o15'-116030' Bujur Timur. Kondisi alam di kabupaten Kotabaru sangat bervariasi. Terdiri dari perpaduan tanah pegunungan dan daerah pantai (genangan) serta daerah daratan dengan daerah perairan yang dipenuhi pulau-pulau kecil. Kabupaten Kotabaru dengan wilayah seluas $9.422,46$ $\mathrm{km} 2$ merupakan kabupaten terluas di propinsi Kalimantan Selatan dengan luas lebih dari seperempat $(25,11 \%)$ dari luas wilayah propinsi Kalimantan Selatan. Kabupaten ini terbagi menjadi 21 kecamatan dengan 198 desa dan 4 kelurahan. luas Area: 9.422,46 $\mathrm{km} 2$

Kecamatan

Hampang merupakan kecamatan terluas di Kabupaten Kotabaru (menempati 17,88\% dari luas wilayah). Kecamatan Pulau Sembilan merupakan kecamatan dengan luas terkecil di Kabupaten Kotabaru (hanya menempati $0,05 \%$ dari luas wilayah).

Kabupaten Kotabaru adalah salah satu kabupaten yang berada di provinsi Kalimantan Selatan, Indonesia. Ibu kota kabupaten ini terletak di Kotabaru yang terletak di Pulau Laut, pulau yang terpisah dari pulau Kalimantan. Kabupaten ini merupakan salah satu kabupaten pertama dalam provinsi Kalimantan dahulu. Dan pada masa Hindia Belanda merupakan Afdeeling Pasir en de Tanah Boemboe dengan ibu kota Kota Baru. Kabupaten ini memiliki luas wilayah 9.442,46 $\mathrm{km}^{2}$ dan berpenduduk sebanyak 290.142 jiwa (hasil Sensus Penduduk Indonesia 2010) dengan nelayan laut sebanyak 15.961 jiwa, dan pada tahun 2020, penduduk kabupaten Kotabaru berjumlah 325.571 jiwa. Motto daerah ini adalah "Saijaan" (bahasa Banjar) yang memiliki arti: Semufakat, satu hati dan se-iya sekata. Di Kabupaten Kotabaru terdapat berbagai macam suka, yaitu; Suku Banjar, Suku Bugis, Suku Mandar, Suku Bajau, Suku Dayak Bukit, Suku Dayak Samihim, Suku Jawa, dan Suku Tionghoa-Indonesia.

Umat Buddha di Buluh Kuning saat ini lumayan banyak, dibandingkan masuknya Agama Buddha. Mereka juga cukup aktif dalam mengikuti kegiatan yang ada di Vihara, misalnya saja pada saat puja bakti hari minggu dan remajanya puja bakti malam sabtu. Perayaan hari-hari besar Agama Buddha, serta biasanya juga menghadiri undangan dari Vihara-vihara lainnya pada saat acara Waisak bersama.

Oleh karena itu, perlu adanya dilaukan pembinaan agar dapat memperkokoh umat, membuat umat semakin aktif dan tidak ada 
yang pindah Agama lagi. Kebanyakan umat yang memilih berpindah Agama karena kurangnya pengetahuan, serta pembinaan yang dapat memberikan pelajaran baru kepada umat. Maka dari itu, harus ada pembinaan dari para tokoh-tokoh yang lebih berpengalaman dalam Agama, terutama kepada generasi penerus yang nantinya dapat membawa perubahan bagi kemajuan umat Buddha di Desa Buluh Kuning.

Karena generasi peneruslah yang masih membutuhkan banyak pembinaan, yang dapat menambah pengetahuan mereka mengenai Agama, maka dari itu pada saat ini kunjungan di Vihara selalu ada kegiatan puja bakti malam yang kemudian diisi dengan Dhammadesana atau uraian Dhamma, serta memberikan motivasi kepada para umat. Sehingga akan membuat umat lebih aktif dan bisa mengemukakan pendapatnya tanpa ada rasa malu dan canggung.

Setelah dilakukan penelitian yang secara online, akan diuraikan beberapa hasil penelitian yang diperoleh. Pembahasan hasil penelitian ini penulis akan membahas peran guru terhadap kemajuan umat Buddha di Vihara Buluh kuning sehingga dapat memperkokoh keyakinan terhadap Buddhadhamma.

Dari data yang diperoleh, penulis akan menguraikan mengenai puja bakti di Vihara Buddha Manggala Desa Buluh Kuning, mengenai kegiatan yang dilakukan oleh para umat Buddha untuk dapat menambah keyakinan umat sehingga kokoh. Umat Buddha mempunyai peran yang penting dalam mengaktifkan dan mengembangkan kegiatan puja bakti, serta terus mengikuti kegiatan puja bakti, baik pada saat hari minggu maupun pada puja bakti anjangsana. Pertanyaan tersebut nampak dari hasil wawancara yang dilakukan pada tanggal 20 April 2020 dengan Bapak Duhan selaku Ketua Vihara Buddha Mangala Desa Buluh Kuning. Bapak Duhan mengatakan Bahwa;
"Umat Buddha dalam kegiatan puja bakti sangat mempunyai peran penting. Sehinggaitu juga ada kegiatan berkumpul bersama dan melakukan puja bakti untuk meningkatkan kemajuan Agama Buddha, serta meningkatkan pengetahuan umat mengenai ajaran Agama Buddha dan juga dapat mempraktikkannya dalam kehidupan sehari-hari”.

Pernyataan yang sama juga disampaikan oleh bapak Hasim selaku umat Vihara Buddha Manggala Desa Buluh Kuning beliau mengatakan bahwa: "Mengikuti puja bakti secara rutin, mengadakan kegiatan yang bermamfaat bagi semua umat serta memberikan ceramah-ceramah Dhamma agar dapat memperkokoh keyakinan umat terhadap Buddhadhamma.

Dari dua pernyataan tersebut maka penulis memberikan penjelasan bahwa peran seorang guru dalam mengadakan kegiatan puja bakti adalah membimbing umatnya agar semangat datang ke Vihara sehingga dapat memperkokoh keyakinannya terhadap Buddhadhamma, sehingga tidak memungkinkan umat untuk berpindah keyakinan.

Berdasarkan hasil penelitian yang sudah dilakukan di Desa Buluh Kuning, kegiatn puja bakti merupakan kewajiban bagi seorang guru serta umat-umat yang ada di Desa Buluh Kuning, sehingga kegiatan ini harus terus dilaksanakan dan dikembangkan lagi. Dengan demikian maka, generasi penerus tidak mudah pindah Agama, karena memiliki bekal yang didapat selama mengkuti kegiatan yang ada di Vihara maupun di rumah umat. Hal ini bisa dilakukan dengan cara memberikan ceramah Dhamma ataupun mengundang tokoh yang memang sudah berpengalaman dalam menyampaikan Dhamma serta memberikan motivasi kepada penerus agar terus maju dalam Dhamma dan terus yakin dengan 
Jurnal

Agama Buddha, sehingga dapat menjadi generasi penerus yang baik.

Perkembangan Agama Buddha di Desa Buluh Kuning menjadi tolak berdirinya Vihara Buddha Manggala. Karena Vihara merupakan tempat utama yang dapat digunakan untuk mengembangkan Agama Buddha dan juga untuk memperkenalkan ajaran Agama Buddha yang lebih luas lagi. Hal ini dapat dilakukan dengan mengadakan dikusi, misalnya saja ada seorang Bhikkhu yang datang berkunjung maupun para Dhammaduta lainnya ataupun penyuluh yang datang. Kegiatan yang dolakukan di Vihara dapat membantu semangat mereka datang ke Vihara. Meskipun tidak semua umat mengikuti kegiatan di Vihara, akan tetapi sebagian besar dari mereka masih bersemangat untuk mengikuti kegiatan yang ada. Kegiatan tersebut tentu akan membantu untuk memperkokoh keyakinan mereka.

Peran guru Agama Buddha dalam memperkokoh umat Buddha bisa dilakukan dengan mengadakan kegiatan yang dapat membuat umat semakin kokoh, yakni dengan membabarkan Dhamma baik pada saat puja bakt di Vihara maupun puja bakti anjangsana. Membina umat dalam pengalaman ajaran Agama Buddha sesuai dengan kitab suci serta memberikan pejelasan tentang ajaran Sang Buddha sehingga dapat membuat umat kokoh dalam Agama Buddha.

Pernyataan tersebut tak jauh berbeda dengan apa yang disampaikan oleh Bapak Adhi. Bapak Adhi mengatakan bahwa: "Memberikan motivasi kepada umat, agar memiliki keyakinan yang kuat terhadap Agama Buddha. Serta mengadakan kegiatankegiatan yang menambah semangat semua umat, serperti mengadakan gotong royong dan kunjungan ke rumah umat-umat.

Berdasarkan hasil wawancara dapat diketahui bahwa, peran guru Agama Buddha dalam memperkokoh keyakinan umat sangatlah penting. Hal ini dapat dilakukan dengan cara memberikan suatu mitivasi yang dapat membuat umat semakin yakin dan tdak mengalami ke mindinderan karena hidup di lingkungan dengan Agama minoritas. Oleh karena itu, perlu adanya kegiatan yang dapat memberikan motivasi kepada umat untuk tetap bertahan dengan keadaan yang ada. Hal ini dapat mengundang para Bhante, Samanera maupun para Atthasilani, sehingga umat mendapatkan pengetahuan baru mengenai Agama yang di anutnya selama ini.

\section{KESIMPULAN}

Dari penyaji data dan pembahasan hasil penelitian sebagaimana bab diatas, maka dapat disimpulkan bahwa, "Signifikansi Guru Agama Buddha Vihara Buddha Manggala dalam Memperkokoh Keyakinan Umat Buddha Terhadap Buddhadhamma. Peran guru Agama Buddha ini sangat penting dan juga sangat bermamfaat bagi umat-umat yang ada di desa. Berkat adanya guru Agama Buddha sebagai pembimbing umat agar tetap kokoh keyakinannya terhadap Buddhadhamma.

Dengan adanya Guru Agama Buddha yang bertangung jawab dalam miningkatkan keyakinan serta memberikan motivasi agar umat terus semangat datang ke Vihara Dengan demikian umat akan menjadi semakin yakin terhadap Agama yang dinanutnya sehingga tidak mudah berpindah keyakinannya terhadap ajaran Sang Buddha.

\section{DAFTAR PUSTAKA}

Armai Arif. (2002). Pengantar Ilmu dan Metode Pendidikan Islam. Jakarta: Ciputat Pers.

Arikunto. (2006). Prosedur Penelitian: Suatu Pengantar Praktik. Jakarta: Rineka Cipta 
Jurnal

Agama Buddha dan Ilmu Pengetahuan

Vol. 4, No 1, Juli 2021: 1-7

Arikunto Suharsimi. (2002). Prosedur Penelitian Suatu Pendekatan Praktik-Edisi revisi V. Jakarta: Rineka Cipta.

Bungin. (2007). Penelitian Kualitatif. Jakarta: Prenada Media Group.

Basyirudin Usman. (2002). Metode Pengajaran Agama Islam. Jakarta: Ciputat Pers.

Dhammananda, Sri. (2005). Hidup dan Masalahnya. Jakarta: Ehipassiko.

Danim, Sudarwan dan Khairil. (2013). Profesi Kependidikan. Bandung: Penerbit Alfabeta.

Mulyani Sumantri Pernama Johar. (2001). Buku Strategi Belajar Mengajar. Bandung: CV.Maulana.Hartono Kasnadi. (1989). Teknik Mengajar. Semarang: IKIP Semarang Press.

Gulo, Herman. S. (1997). Hari Raya Buddha dan Kalender Buddhis 1996-2026. Jakarta: Yayasan Dhammadipa Arama.

Halim Oktaviani Metta. (2014). Dhammadana Para Dhammaduta 4. Yogyakarta: Vidyasena Production.

Kusaladhamma. (2009). Illustrated Chronicle of The Buddha. Diterjemahkan oleh Hendra Widjaja. Jakarta: Ehipassiko Foundation.

Kamus Umum Bahasa Indonesia. (2005). Jakarta: Balai Pustaka.

Miles, B. M., dan Huberman, M. (1992). Amalisis Data Kualitatif Buku Sumber Tentang Metode-metode Baru. Jakarta: UIP. Mulyasa. (2009). Implementasi Kurikulum Tingkat Satuan Pendidikan. Jakarta: Bumi Aksara.

Margono. (2004). Metode Penelitian Pendidikan. Yogyakarta: Pustaka Belajar.

Margono S. (2007). Metode Penelitian Pendidikan Komponen MKDK. Jakarta: PT.Rineka Cipta.

Moleong, Lexy. (2017). Metode penelitian Kualitatif. Bandung: PT Remaja Rosdakarya.

Nazir, Moh. (1998). Metode Penelitian. Jakarta: Ghalia Indonesia.

Nanamoli, Bhikkhu. (2006). Khuddakapatha Kitab Suci Agama Buddha Bagian 2. Klaten: Wisma Samabodhi.

Uttamo. (2004). Tanya Jawab dengan Bhikkhu Uttamo. Blitar: Vihara Samagi Jaya.

Roestiyah. (1991). Strategi Belajar Mengajar. Jakarta: Rineka Cipta.

Suparta Hm dan Herry Noer. (2003). Metode Pengajaran Agama Islam, Jakarta: Amisco.

Sumiarti dan Asra. (2013). Metode Pembelajaran, Bandung: Wacara Prima.

Nasution. (1982). Berbagai Pendekatan Dalam Proses Belajar Dan Mengajar. Jakarta: Bina Ilmu Aksara.

Sulani. (2011). Buku Pendidikan Agama Buddha Sekolah Dasar Dharmacakra kelas 4. Jakarta: CV. Karunia Jaya.

Sugiyono. (2001). Statistika Untuk Penelitian. Bandung: Alfabeta.

Sugiyono.(2005). Memahami Penelitian Kualitatif. Bandung: Alfabeta.

Sugiyono. (2007). Metode Penelitian Pendidikan Kuantitatif, Kualitatif. Bandung: Alfabeta. 
Jurnal

Agama Buddha dan Ilmu Pengetahuan

Vol. 4, No 1, Juli 2021: 1-7

Trigis, Buntario. (1998). Mengapa Kita

Harus Berdana. Jakarta: Yayasan

Dhammadasa.

Undang Undang Nomor 14 Tahun 2005

Tentang Guru dan Dosen. 